\title{
Information systems research methodologies and models
}

\author{
Albertas Caplinskas, Olegas Vasilecas
}

\begin{abstract}
:
The paper argues that one of shortcomings of majority of the current doctoral study programs in information systems is insufficient attention to research methodology. Information systems is an emerging scientific discipline and, consequently, it is still not obvious what amount of knowledge on research issues should be included in the doctoral study program. The paper discusses the body of knowledge in this field recommended for doctoral students in information systems. It is based on two years experience in teaching the module "Research principles and methods" for doctoral students in information systems field.

Key words: doctoral studies, research methodologies, information systems research
\end{abstract}

\section{INTRODUCTION}

One of the most important goals of doctoral studies is to develop the abilities of pursuing original research in the field of study, relating particular research projects to the general body of knowledge in the field, and presenting the results of the researches in a critical and scholarly way [14], [32]. Therefore research philosophy, research methodology and research models play an important role in any doctoral studies. However, information systems (IS) is an emerging scientific discipline and, consequently, it is still not obvious what amount of knowledge on research issues should be included in the doctoral study program. This paper aims to discuss the body of knowledge on research issues that, in our opinion, is reasonable to provide for doctoral students in IS field. Our suggestions are based on two years experience in teaching the module "Research principles and methods" for doctoral students.

\section{Main requirements}

A person having studied the material covered by the module "Research principles and methods" is expected to be able:

- describe and critically analyse the principal methods and strategies employed in research;

- apply the scientific method to solve research and engineering problems;

- use logical analysis as an aid to the coherent organization and persuasive expression of ideas;

- immediately chose a point at which to begin reasoning, construct well-ordered chains of reasoning;

- analyse an argument, detect use of basic logical fallacies,, compare and evaluate different arguments;

- use methods of direct proofs, proofs by counterexample, proofs by contraposition, and proofs by contradiction to articulate a personal position;

- observe, perceive, analyse, evaluate, and conceptualise phenomena;

- decompose given phenomena into its component parts or elementary qualities, reason about phenomena, formulate and test hypothesis;

- identify information needed to address problem, locate information through information source, analyse, verify and evaluate information, and document information;

- identify interfaces, boundaries and components of problems, apply system concepts to definition and solution of problems, break large problems into subproblems, model problem at different abstraction levels;

- form new concepts on the basis of experience or of other concepts, apply relevant old knowledge to the new problems;

- prepare and manage research projects;

- produce research reports and documents of technical nature. 
The main requirements in itself are not specific for IS discipline and can be applied for any other field because the main goal of any doctoral studies is to form a scientist. However, priorities and nature of abilities are highly specific for every particular discipline. For example, methods of observation and phenomena analysis are quite different in the physic and in the IS discipline.

\section{Body of Knowledge}

The module "Research principles and methods" has 6 credits. It comprises of 12 submodules of approximately equal size:

- main characteristics of research work;

- ethical issues of research work;

- phenomena analysis;

- theoretical research methods;

- experimental research methods;

- constructive research;

- problem solving;

- information retrieval;

- data gathering;

- research project management;

- fundamentals of scientific and technical writing;

- logic in science and scientific writing.

Similarly as in the case of requirements, the list of sub-modules is standard for all research fields. In addition, the importance of sub-modules is also approximately this same for all research fields. Differences lie in the content of some sub-modules. For example, even traditions in scientific writing in some extent differ in different sciences. In other words, we argue that the module "Research principles and methods" should be designed or at least tailored for any particular doctoral study program.

It should be noted that all sub-modules could be divided into two groups: submodules that are strongly IS-oriented and sub modules that are more or less independent from the particular research field. To the first group belong sub-modules on phenomena analysis theoretical research [23], [25], experimental research [4], and constructive research. To the second group belong sub-modules on main characteristics of research work, ethical issues of research work, problem solving, information retrieval, data gathering, research project management, fundamentals of scientific and technical writing, logic in science and scientific writing. However our two years experience in teaching of proposed module demonstrated that it is reasonable, even essential, to teach the second group of sub-modules also from IS perspective. Thus we argue that the wide-spread practice when the all doctoral students in the university study research methodology according to the same program prepared without orientation to the peculiarities of the specific research field is not effective.

Let us consider both groups of proposed sub-modules in more details.

The sub-module "Characteristics of research work" is introductory one. It discusses what is the science, the protoscience and the pseudoscience, how the science is related to mathematics, technology, philosophy, ideology and arts, what are the limits of cognition and science, what is a purpose of research work, and in which differ fundamental and applied research and what is the specific of research in IS field. The sub-module pays great attention to the question how individual's knowledge enters the domain of science and discusses shortly most important research philosophies including rationalism, empirism, agnosticism, Kant's philosophy, positivism, pragmatism, relativism, behaviourism, holism, and constructivism. The special attention is paid to second order cybernetics, radical constructivism, and information systems epistemology. The submodule presents the backgrounds of the scientific method including its limits and criticisms. It explains the differences between research principles, methods and discusses 
specifics of qualitative and quantitative research. Finally, the sub-module surveys models of research process. The main attention in this question is paid to the models of library research and IS research.

The sub-module "Ethical issues of research work" discusses research ethics as well as ethics in research. Research ethics provides topics on values conflicts, science commercialisation, ethical issues of scientific and technological progress, and scientist's social and moral responsibility. Ethics in research discusses plagiarism, authorship and co-authorship, student-adviser relations in doctoral research, and issues of intellectual and industrial property, fair use, and the concept of public domain. Issues of IS ethics are not discussed in this module because we suppose that information systems ethics is the subject of master study program.

The sub-module "Phenomena analysis" is one of sub-modules, which are most oriented to the IS field. It discusses issues of observation, perceiving, analysis, evaluation and conceptualisation of a given phenomena. The module acquaints students with impact of cognitive and cultural bias in observation and with the approach of radical constructivism to observation methodology. The sub-module pays special attention to the question that there is a tendency for the mind to envision or construct what is expected to see. It explains differences between formative and summative evaluation of observations and how one can unpack his own assumptions about the observed phenomena. The submodule emphasises the role of Constructivist-Interpretive-Qualitative Paradigm appropriate for evaluating the complexity of systems and organisations. It discusses various evaluation models, and evaluation methods and strategies. The strong emphasis is made on the issues of conceptualisation and the role of formal ontologies in conceptualisation of the observed phenomena.

The sub-module "Theoretical research methods" discusses induction and deduction, grounded theory, modelling, mathematical research, case study, phenomenography, comparative analysis, conceptual analysis, contextual analysis, longitudinal research, and ethnographic and other qualitative approaches. It concentrates on the methods related to research in IS field, namely, on: conceptual modelling [16], [30], ethnographic research [13], grounded theory [17], interpretative research [9] and other qualitative research techniques [29]. The sub-module also emphasises the role of comparative analysis methods in doctoral study research and extensive discusses different comparative analysis techniques.

Experimental research in IS field, mostly, is used to evaluate the available tools and techniques. As pointed in [1], thus field experiments in the field of IS research play key role and should be studied by doctoral students first of all. The sub-module "Experimental research methods" discusses the concept of controlled experiment, field methods, hypothesis testing, and computational research. It is strongly oriented to the IS research field. Similarly as sub-module "Theoretical research methods", it also concentrates on the methods related to research in IS field, including experimental simulation, laboratory experiment, field experiment, adaptive experiment, and field study. Some attention is paid also to computational research.

According to [22], "The constructive research approach is a research procedure for producing innovative constructions, intended to solve problems faced in the real world and, by that means, to make a contribution to the theory of the discipline in which it is applied." It should be noted that "the constructive research can also be viewed as a one form of conducting case research parallel to ethnographic, grounded theory, theory illustration, theory testing and action research." [22] Thus constructive research is one of most important methods in the IS research field. The sub-module "Constructive research" explains how one should understand design as research program and discusses such issues as the building process, evaluation of construction results, and action research. It concentrates on the methodology of the constructive research and on its challenges. It 
emphasises that one of the most serious dilemmas in the constructive research is the scientist's ability to maintain a neutral, even critical, attitude, expected of the scientist during the overall process of development and implementation of the innovative construction. Especial attention is paid also to action research [2] that plays so important role in IS research field. The sub-module discusses similarities and differences between constructive research and action research and emphasises that in both cases the direct and pragmatic empirical connections, and the application of case study method, play a major role. [22]

Problem solving is the ability to select and combine previously learned principles, procedures, declarative knowledge, and cognitive strategies to solve unknown problems. Usually problem solving is studied in Al context. Thus the sub-module "Problem solving" in some sense extends the master-level Al course. However it concentrates on slightly different issues, namely, sees problem solving in the context of scientific research and, consequently, discusses such questions as the use of relevant old knowledge to the new problems and forming new concepts on the basis of experience and of other concepts. Especial attention is paid to the issues of problem identification and definition, human problem solving process and creative thinking.

The sub-module "Information retrieval" covers traditional issues on information retrieval in the context of scientific research and discusses problems how to determine what information is needed to address a given problem, how to search and to review relevant literature sources, and how to analyse, evaluate and record the collected information. Especial attention is paid to the research tools such as research guides, handbooks and encyclopedias in the field of IS (e.g. [5], [7], [31]). The sub-module acquaintances also with the tools of search the scientific papers in Internet (IS World [18], DB\&LP[14], ACM Guide [28], The Collection of Computer Sciences Bibliographies [27], CiteCeer [26], BibFinder [6], etc.)

The sub-module "Data gathering" discusses data gathering techniques, modes of analysis, including hermeneutics and semiotics [24], [21]and narrative and metaphor [3], [8], [11], [19], statistical data processing, and other data analysis methods.

The sub-module "Research project management" introduces the notion of research project and familiarises with issues of research planning, proposals writing, and research project monitoring and evaluation.

The sub-module "Fundamentals of scientific and technical writing" discusses the strategies and mechanics for writing, the structure of research reports and articles and issues of simplification of complex technical materials and separation of concerns. Special attention is paid to the specific of writing the doctoral thesis.

The sub-module "Logic in science and scientific writing" continues issues of previous sub-module. It explains how to use logical analysis as an aid to the coherent organisation and persuasive expression of ideas, how to choose a point at which to begin reasoning, how to construct the well-ordered chains of reasoning, how to keep the sight of goal while thinking through the problem, and discusses argumentation techniques and logical fallacies. It also acquaints with the approaches how to relate the topic's significance to the wider academic context.

\section{CONCLUSIONS}

Research methodology and techniques in the field of information systems comparing to other research fields are not less important. Current state of research in IS is already enough mature [10], [19], [11] to sort out what is more and what is less significant in this field. Hence doctoral study program in IS discipline should provide a module on research methodology and research techniques. Although the main topics of such module are the same for any research field, its contents depend significantly on the specific of the particular research area. Thus, on our view, the module for the doctoral studies in IS, should be carefully designed for this aim. Our experience demonstrate that the wide- 
spread practice when the all doctoral students in the university study research methodology according to the same program prepared without orientation to the peculiarities of the specific research field is not effective.

\section{REFERENCES}

[1] R. Agarwal, D. Batra, I. Vessey, Y. Wand. Experimental research in systems development methodologies: opportunties and challenges. In: Fifteenth International Conference on Information Systems, December 14-17, 1994.Panel Presentation

[2] D. Avison, F. Lau, M. D. Myers, P.A. Nielson. Action Research. Communications of the ACM, 1999, Vol. 42, No. 1, 94-97.

[3] C.M. Beath, W.J. Orlikowski. The Contradictory Structure of Systems Development Methodologies: Deconstructing the IS-User Relationship in Information Engineering. Information Systems Research, 1994, Vol. 5, No4, 350-377.

[4] I. Benbasat. The Information Systems Research Challenge: Experimental Research Methods (Harvard Business School Research Colloquium). Harvard Business School Press, 1991

[5] P. Bernus, K. Mertins, G. Schmidt (eds.). Handbook on Architectures of Information Systems (International Handbooks on Information Systems). Springer-Verlag, 1998.

[6] BibFinder. A Computer Science Bibliography Mediator (maintained by Zaiqing Nie), Arizona State University, http://kilimanjaro.eas.asu.edu/

[7] H. Bidholi. Encyclopedia of Information Systems. Academic Press, 2002

[8] R.J. Boland, R.H. Greenberg. Metaphorical structuring of organizational ambiguity. In: L.R. Pondy, R.J. Boland, H. Thomas (eds). Managing Ambiguity and Change, Chilchester, Wiley, 1988, 17-36.

[9] T. Butler. Towards a hermeneutic method for interpretive research in information systems. Journal of Information Technology, 1998, Vol.13, No. 4, 285-300.

[10] P. Checkland, S. Holwell. Information, Systems and Information Systems: Making Sense of the Field. Wiley, 2002

[11] B. Dahlbom, L. Mathiassen. Computers in Context. The Philosophy and Practice of System Design. Blackwell, 1996.

[12] E.J. Davidson. Examining Project History Narratives: An Analytic Approach. In: Information Systems and Qualitative Research, A.S. Lee, J. Liebenau and J.I. DeGross (eds.), Chapman and Hall, London, 1997, 123-148.

[13] L. Davies, M.D. Myers. Scholarship and practice: the contribution of ethnographic research methods to bridging the gap. In: B.C. Glasson, I.T.

Hawryszkiewycz, B.A. Underwood and R.A. Weber (eds.). Business Process ReEngineering: Information Systems Opportunities and Challenges. North Holland, 1994, 223-231.

[14] DBLP (Computer Science Bibliography maintained by Michael Ley). 19982004, http://dblp.uni-trier.de/

[15] A.R. Dennis, J.S. Valacich. Conducting Research in Information Systems. Communications of the Association for Information Systems, 2001, Vol.7, article 5, http://cais.isworld.org/articles/7-5/default.asp?View=pdf\&x=46\&y=6.

[16] U. Frank. Conceptual Modelling as the Core of the Information Systems Discipline -Perspectives and Epistemological Challenges. In: D.W. Haseman, D. Nazareth, D. Goodhue (eds.): Proceedings of the Fifth America's Conference on Information Systems (AMCIS99). AIS, Milwaukee 1999, 695-697

[17] J. Hughes, D.A. Howcroft. Grounded Theory: Never Knowingly Understood. Information Systems Review, 2000, 1, 181-197.

[18] IS World. Association for Information Systems, http://www.isworld.org/

[19] J.E. Kendall, K.E. Kendall. Metaphors and Methodologies: Living Beyond the Systems Machine. MIS Quarterly, Vol. 17, No.2, 1993, pp. 37-47 
[20] D. Khazanchi, B.J. Munkvold. Is Information Systems a Science? An Inquiry into the Nature of the Information Systems Discipline. The DATA BASE for Advances in Information Systems, 2000, Vol. 31, No. 3, 24-42

[21] K. Liu, R. J. Clarke, P.B. Andersen, R.K. Stamper, El-Sayed Abou-Zeid. Organizational Semiotics Evolving a Science of Information Systems. 2002

[22] K. Lukka. The constructive research approach. In: L. Ojala, O-P. Hilmola. (eds.) Case study research in logistics. Publications of the Turku School of Economics and Business Administration, Series B 1: 2003, p. 83-101.

[23] J. Mingers. Combining IS Research Methods: Towards a Pluralist Methodology. Information Systems Research, 2001, Vol.12 No. 3, 240-259.

[24] M. D. Myers. Dialectical Hermeneutics: A Theoretical Framework for the Implementation of Information Systems. Information Systems Journal, 1995, Vol.5, No. 1, 51-70.

[25] H-E. Nissen, H.K. Klein, R.A. Hirschheim (eds.). Information Systems Research: Contemporary Approaches and Emergent Traditions. North-Holland, 1991.

[26] Scientific Literature Digital Library. NEC and IST, http://citeseer.ist.psu.edu/cis

[27] The Collection of Computer Sciences Bibliographies. Alf-Christian Achilles, 1995-2004, ,http://liinwww.ira.uka.de/bibliography/index.html

[28] The Guide to Computing Literature. ACM, http://portal.acm.org/guide.cfm

[29] E.M. Trauth (ed.). Qualitative Research in IS: Issues and Trends. Idea Group Publishing, Hershey, PA, 2001.

[30] Y. Wand, R. Weber. Research Commentary: Information Systems and Conceptual Modeling-A Research Agenda. INFORMS, 2002, Vol. 13, No. 4, 363-376

[31] M.E. Whitman, A.B. Woszczynski, M.E. Whiman. The Handbook of Information Systems Research. Idea Group Publishing, 2003.

[32] A.M. Wilkinson. The Scientist's Handbook for Writing Papers and Dissertations. Prentice Hall, 1991

\section{ABOUT THE AUTHOR}

Prof. Albertas Caplinskas, Dr, Department of Information Systems, Vilnius Gediminas Technical University, Phone: +37052626107, E-mail: ALCapl@klt.mii.It.

Prof. Olegas Vasilecas, Dr, Department of Information Systems, Vilnius Gediminas Technical University, Phone: +37052744859, E-mail: olegas@fm.vtu.It. 